\title{
Wir gratulieren Herrn Prof. Dr. med. Georg Brehm zu seinem 80. Geburtstag am 25. Oktober 2004
}

Congratulation to Prof. Dr. med. Georg Brehm at his $80^{\text {th }}$ Birthday on 25. 10. 2004

Georg Brehm wurde am 25.10.1924 als Sohn eines Dermatologen-Ehepaares in Reval, der Hauptstadt von Estland, geboren und verbrachte dort die ersten 17 Jahre seines Lebens. Es war eine behütete und unbeschwerte Jugend. Seine Vita, seine humanistische, feinfühlige und kompetente Art und seine dermatologischen Verdienste und Erfolge sind zum 65. Geburtstag und anlässlich seiner Verabschiedung durch die Stadt Ludwigshafen 1989 dargestellt und gewürdigt worden [1,2]. Sie werden hier anhand einer Bilderfolge wieder aufgerufen (Abb.1-5).

Im Jahre 1972 wurde Prof. Georg Brehm zum Chefarzt der Hautklinik am Klinikum der Stadt Ludwigshafen gewählt, wo er 17 Jahre fruchtbar und erfolgreich tätig war. Seine dermatologische Kompetenz und die operative Kunst stellte er uneingeschränkt seinen Patienten zu Verfügung. Er erfreute sich bei den ihm anvertrauten Menschen wie auch bei den Kollegen größter Beliebtheit.

Im Jahre 1975 gründete er zusammen mit Hansotto Zaun (Homburg, Saar) und Hans-Joachim Heite (Freiburg i. Br.) unsere Zeitschrift „Aktuelle Dermatologie“, welcher er von Anfang an bis Ende 2001, also 27 Jahre lang, als federführender Herausgeber diente und auch die Redaktion besorgte. Anlässlich seines Ausscheidens wurde vor 3 Jahren Dank und Anerkennung für diese hervorragende Leistung ausgedrückt [3].

Die Abb. 6 zeigt, dass Georg Brehm diese 30 Jahre unverkennbar gut überstanden hat. Er hat seine Jugendlichkeit gewahrt, ist interessiert und agil, aufgeschlossen und hoch kompetent als Dermatologe und als Humanist geblieben. Auch hat er über all die Jahre hinweg seine Liebenswürdigkeit und die vertrauensvolle Art bewahrt. Wahrlich ein kollegialer Freund!

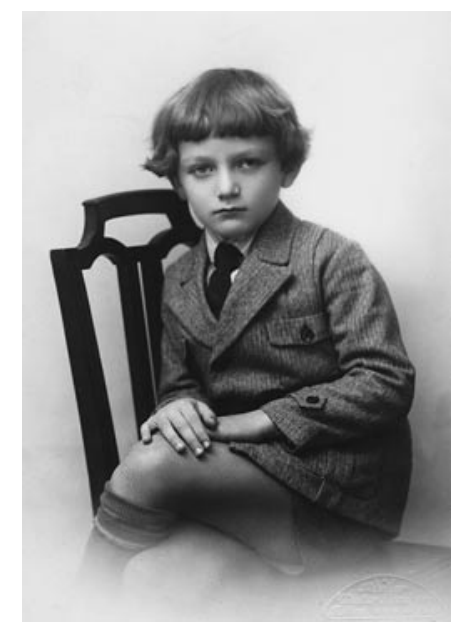

Abb. 1 Der 8-jährige Schüler Georg Brehm im Jahre 1932 in Reval.

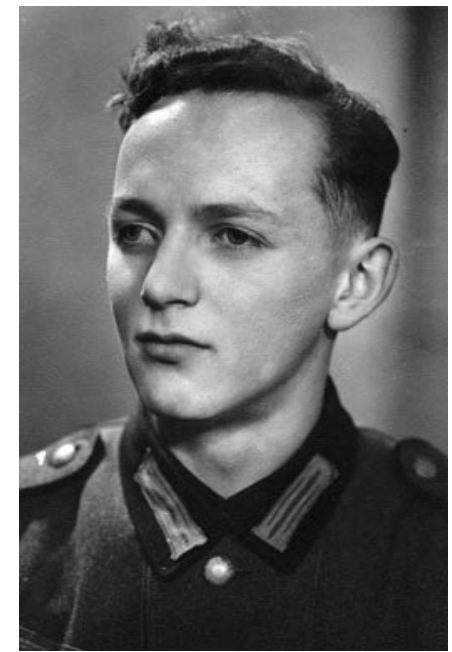

Abb. 2 Georg Brehm 1944 in Uniform. Er studierte Medizin an der Universität Frankfurt von 1943 - 1950, unterbrochen 1944 - 1946 durch Militärdienst und Gefangenschaft. 
Abb. 3 Diese Zeichnung von H. Tümmers aus dem Jahre 1957 zeigt Georg Brehm in charakteristischer Pose beim kontinuierlichen beruflichen Aufstieg. Er absolvierte seine Facharztweiterbildung 1953 - 1961 an der Universitätshautklinik Tübingen (Prof. Heinrich A. Gottron). Die private Erfüllung folgte 1958 durch die Heirat mit der Kollegin Ilse Käppel.

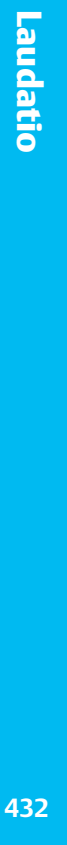

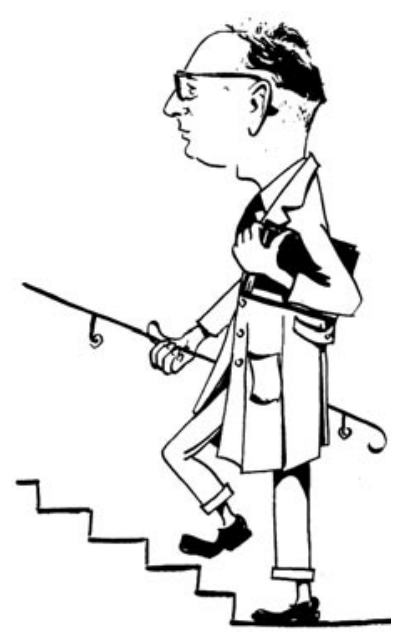

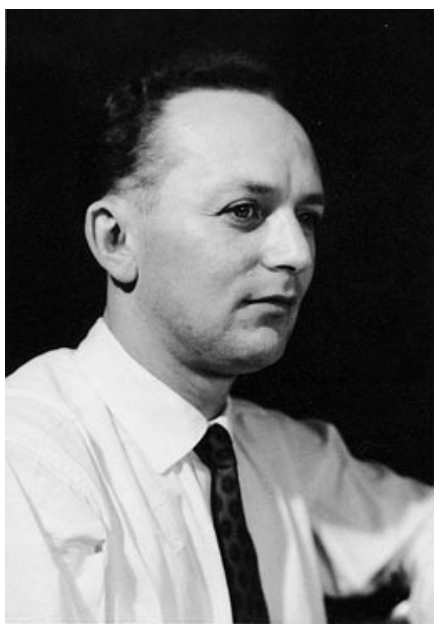

Abb. 4 Der Hautfacharzt Georg Brehm im Jahre 1961.

Er ging 1961 - 1972 als Oberarzt an die Universitätshautklinik Mainz (Prof. Günter W. Korting), wo er sich 1964 habilitierte.

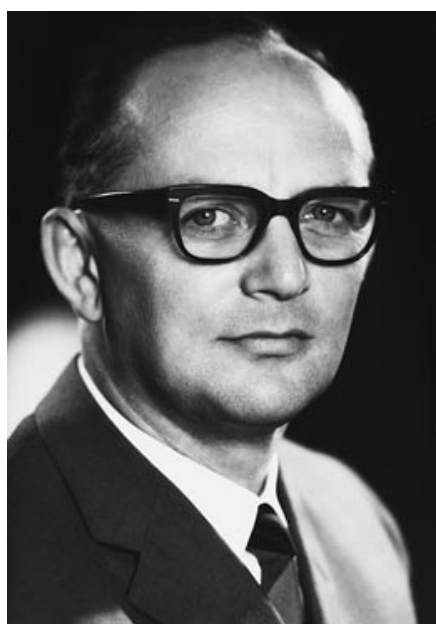

Abb. 5 Prof. Georg Brehm 1972, reif für eine selbstständige Stellung und Leitungsfunktion.
Abb. 7 Prof. Georg Brehm mit seiner Gattin freuen sich auf den bevorstehenden Geburtstag. Wir gratulieren!
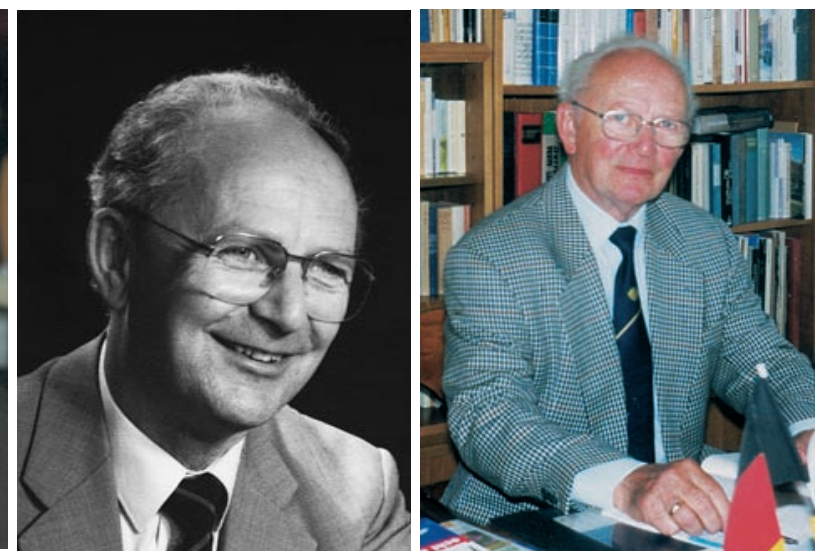

Abb. 6 Prof. Georg Brehm durch die letzten drei Jahrzehnte. a Mit 52 Jahren, anlässlich der Tagung der Südwestdeutschen Dermatologen, die er 1976 in Ludwigshafen mit großem Erfolg ausrichtete. b Im Jahre 1984 anlässlich seines 60. Geburtstages. c Im Sommer 2004 in seinem häuslichen Arbeitszimmer in Vorbereitung auf den 80. Geburtstag am 25. 10. 2004.

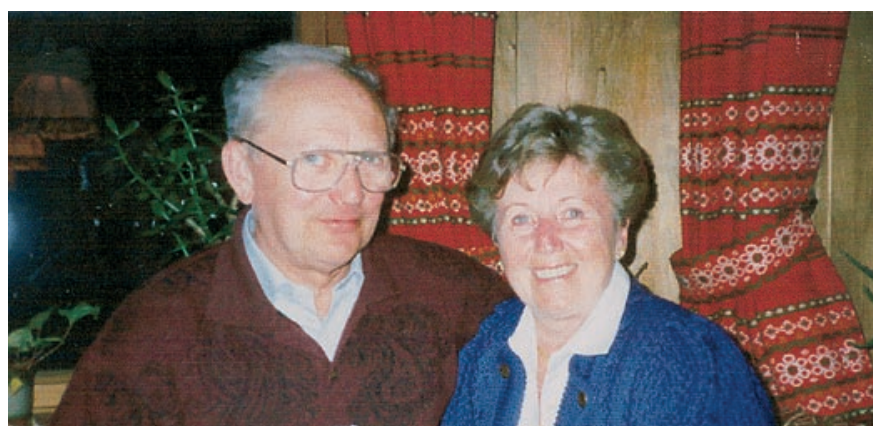

Die Herausgeber der „Aktuellen Dermatologie“ und die Autoren, ebenso wie der Georg Thieme Verlag gratulieren Herrn Professor Georg Brehm, dem Gründer und jahrzehntelangem Motor, aber auch dem Kollegen und Freund, zu seinem 80. Geburtstag am 25.10.2004 von ganzem Herzen. Zufriedenheit, Fröhlichkeit und Wohlbefinden sowie eine rege und anspruchsvolle Betätigung, zu Hause und unterwegs, wünschen wir ihm und seiner Gattin Frau Dr. med. Ilse Brehm (Abb. 7).

Für die Herausgeber:

Prof. Dr. med. Ernst G. Jung

für den Georg Thieme Verlag:

Albrecht Hauff

\section{Literatur}

${ }^{1}$ Jung EG. Georg Brehm zum 65. Geburtstag. Hautarzt 1989; 40: 662

2 Zaun HO. Georg Brehm zum 65. Geburtstag. Akt Dermatol 1989; 15: 269

${ }^{3}$ Jung EG, Hauff A. Prof. Georg Brehm tritt nach 27 Jahren als Herausgeber unserer Fachzeitschrift „Aktuelle Dermatologie“ zurück. Akt Dermatol 2001; 27: 383-384 